\title{
TOTAL STERNECTOMY WITH BILATERAL STERNOCLAVICULAR JOINT EXCISION FOR GIANT CELL TUMOUR STERNUM
}

\author{
Jagadesh Chandra Bose Soundararajan', Periasamy Subbiah², Ramaswamy Rajendran³, Prithviraj Premkumar 4
}

1 Professor and HOD, Department of Surgical Oncology, Madras Medical College, Rajiv Gandhi Government General Hospital, Chennai, Tamilnadu, India.

2Professor, Department of General Surgery, Government Chengalpattu Medical College, Chengalpattu, Tamilnadu, India. ${ }^{3}$ Senior Resident, Department of Surgical Oncology, Madras Medical College, Rajiv Gandhi Government General Hospital, Chennai, Tamilnadu, India.

${ }^{4}$ Senior Resident, Department of Surgical Oncology, Madras Medical College, Rajiv Gandhi Government General Hospital, Chennai, Tamilnadu, India.

\section{ABSTRACT}

A case of giant cell tumour replacing the entire sternum for which total Sternectomy with B/L sternoclavicular joint excision was carried out. This procedure has been done for the first time in the literature. The clinical data are summarized and the surgical technique has been described. After Sternectomy the area of resection was reconstructed with stainless steel plates and screws, prolene mesh and poly methyl methacrylate which assured stability of the chest wall. We discussed the method of reconstruction, technical details and outcome of the procedure in terms of complications and the return of the preoperative level of function.

\section{KEYWORDS}

Sternectomy, Giant Cell Tumour of Sternum, Sternal Tumours.

HOW TO CITE THIS ARTICLE: Soundararajan JCB, Subbiah P, Rajendran R, et al. Total sternectomy with bilateral sternoclavicular joint excision for giant cell tumour sternum. J. Evolution Med. Dent. Sci. 2016;5(41):2557-2559, DOI: $10.14260 /$ jemds/2016/597

\section{INTRODUCTION}

Sternal resection and reconstruction have long been a challenge due to the difficulty making a full thickness resection without compromising the stability and reconstructing the thoracic wall. Reconstruction strategy depends on the site and extent of the resected chest wall defect. Myocutaneous flaps and prosthetic material greatly facilitate after massive chest wall resection. Brodin and Linden first performed and described Total Sternectomy for chondrosarcoma involving the entire sternum. We present this case and procedure, because of its uniqueness that it involves total Sternectomy with B/L Sternoclavicular joint excision with reconstruction, which is being reported for the first time in the literature.

\section{CASE SUMMARY}

A 28-year-old male who presented with a midline swelling in the anterior chest wall for 1-year duration with dull aching type of pain. Swelling was of size $15 \times 8 \mathrm{~cm}$ replacing the entire sternum with irregular surface and variable consistency. Rest of the examinations were normal.

\section{MRI Chest}

Mass replacing the entire sternum with heterogeneous high signal areas with variable low signal intensities in T2 weighted image.

\section{CT Chest}

Osteolytic and destructive mass replacing the entire sternum.

Financial or Other, Competing Interest: None.

Submission 22-03-2016, Peer Review 02-05-2016,

Acceptance 07-05-2016, Published 23-05-2016.

Corresponding Author:

Dr. Ramaswamy Rajendran.

New No. 17, Old No. 6,

$3^{\text {rd }}$ Main Road Gandhi Nagar,

Adyar, Chennai-600020.

E-mail: drramasamy88@gmail.com

DOI: $10.14260 /$ jemds $/ 2016 / 597$

\section{Trucut Biopsy}

Showed features of giant cell tumour.

Vertically elliptical incision from suprasternal space to the xiphisternum inferiorly, swelling was excised in toto with sternal origins of both pectoralis major along with the medial ends of the clavicle and first six costal cartilages and a portion of the anterior parietal pericardium. B/L internal thoracic arteries were ligated.

The defect over the anterior chest wall was reconstructed with 15 holes contoured stainless steel plates with curvatures facing downwards bridging the medial end of the clavicles giving stability to the chest wall. Prolene mesh was placed over the anterior pericardium and anchored to the cut ends of the ribs. Stainless steel wires were tied between the cut ends of the ribs 2, 3, 4, 6; the knots were placed in the midline. The defect was filled with PMMA embedding the knots of the stainless steel wires. Another Prolene mesh was placed over the PMMA layer and anchored to the cut rib surfaces and clavicles above. After placing ICD in both pleural cavities and a suction drain in the chest wall defect site, primary closure of the flaps was done. The stainless steel wires and PMMA layer with the prolene mesh were for additional stability to the chest wall.

In the immediate postoperative period, patient was managed with ventilator support. Patient was weaned out of the ventilator in the $2^{\text {nd }}$ postop day. Patient did not have flail chest or paradoxical movement or disturbance in carrying out his routine activities. CT scan of the chest was done on the postop day 20, which revealed intact contoured plates bridging between the medial ends of the clavicle along with intact stainless steel wires in the defect area, hypodense collection in the anterior mediastinum, segmental atelectasis in the right lower lobe with adjacent pleural thickening, mild pleural effusion on the right side.

Postop histopathology showed a giant cell tumour with adjacent soft tissue tumour infiltration.

Postoperatively, patient's respiratory reserve, pulmonary function tests were normal. His chest wall stability was well 
preserved, serial CT scan/MRI revealed no evidence of recurrent disease.

The patient is on 2 years of follow-up, able to perform his normal day-to-day activities. He is employed as mason and able to perform well in his work without difficulties.

\section{PREOPERATIVE CT IMAGES}

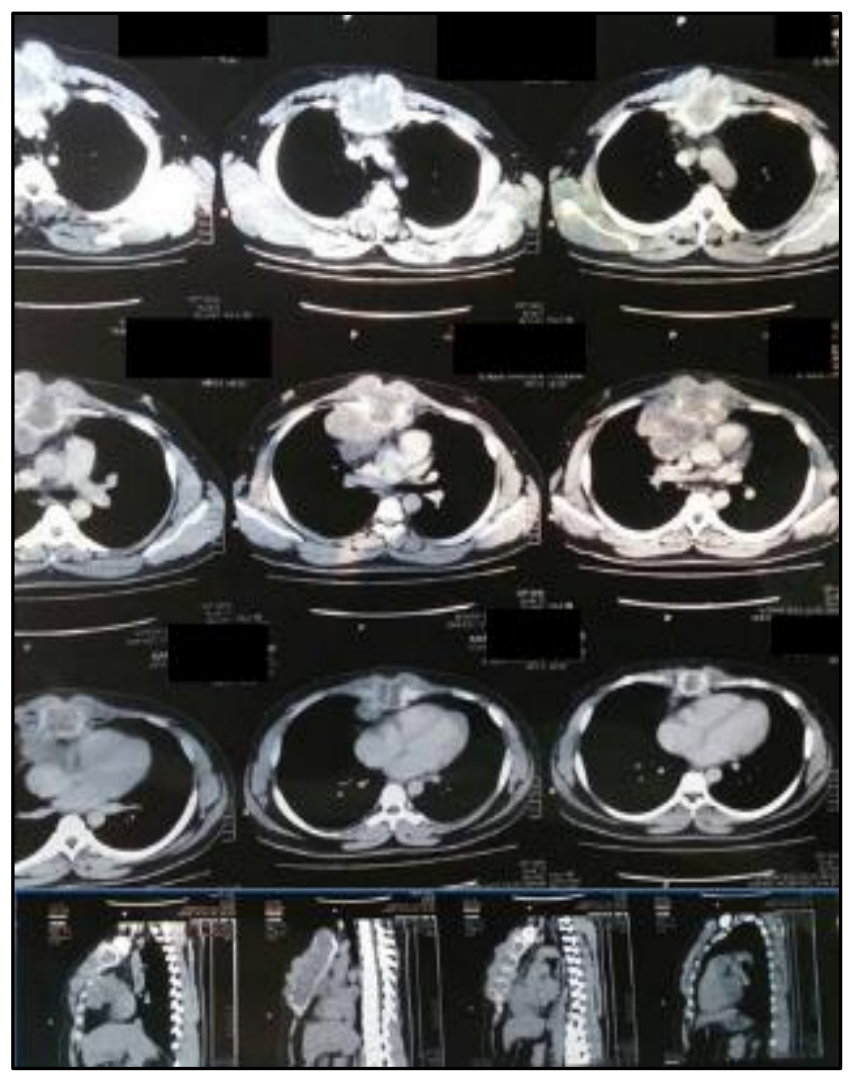

Fig. 1: Osteolytic Lesion Replacing the Entire Sternum with Few Sections showing the Tumour to be Adherent to the Anterior Pericardium

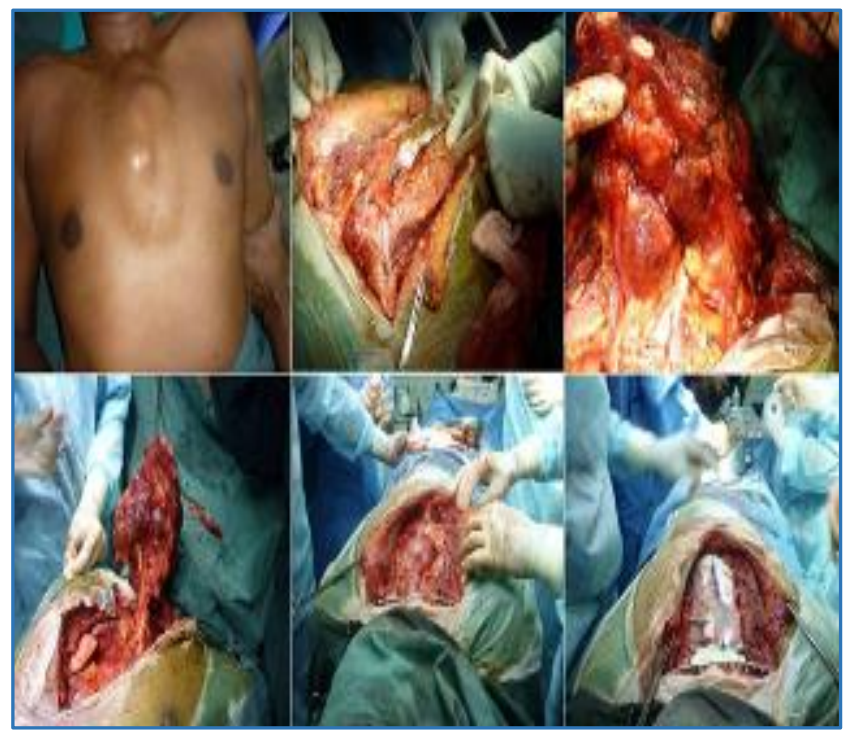

Fig. 2: Operative Procedure showing Resection of the Sternal Tumour followed by Composite Reconstruction with Contoured Stainless Steel Plate, Prolene Mesh and Polymethyl Methacrylate to Restore the Stability of the Chest Wall

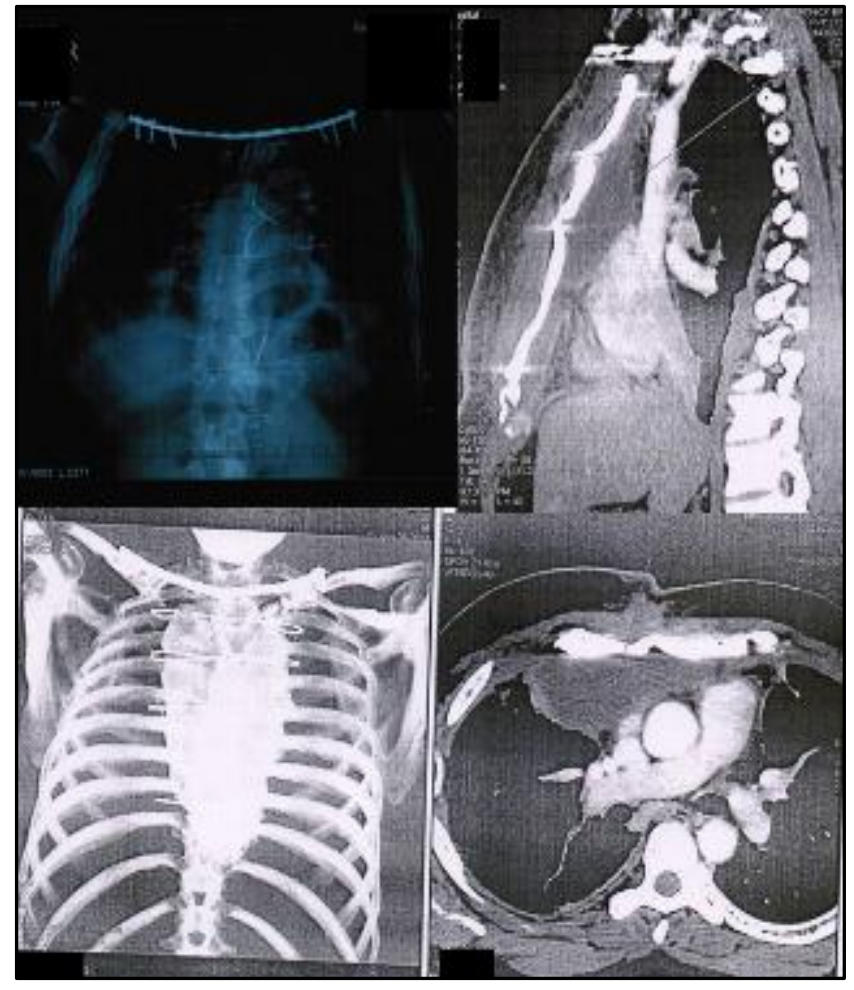

Fig. 3: Post-operative Imaging shows Plates Bridging the Medial Cut Ends of the Clavicle, CT Images shows Minimal Collection in the Retrosternal Area on the Initial PostOperative Period

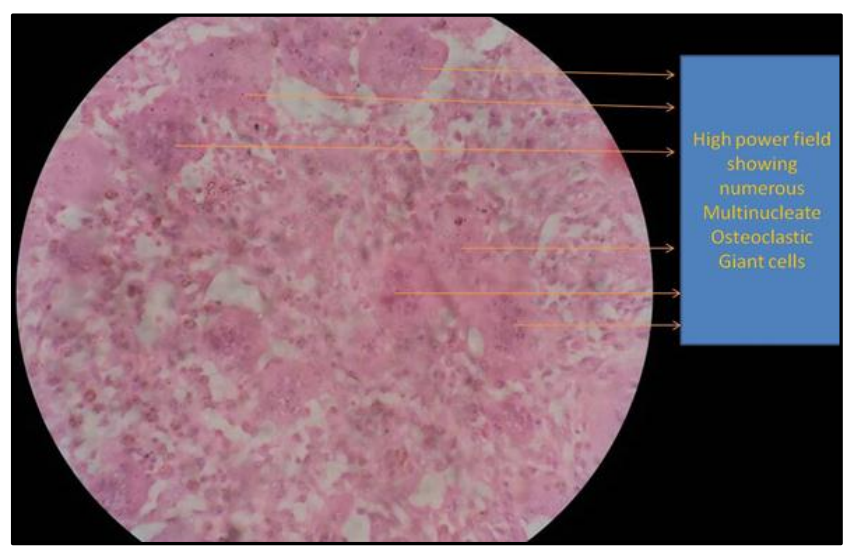

Fig. 4: Microscopic Image showing Numerous Multinucleated Osteoclastic Giant Cells

\section{DISCUSSION}

Benign tumours occurring in the sternum are extremely rare. The common benign tumours are chondroma, fibrous dysplasia, lipoma, aneurysmal bone cyst.(1)

Malignant lesions such as chondrosarcoma, solitary plasmacytoma, metastatic carcinoma, lymphoma, Ewing's tumour, and Desmoid tumour should be excluded because the treatment of malignant tumours differs from the benign tumours and includes a more radical resection.

Of the benign bone tumours, the Giant cell tumour has high recurrence rate and its treatment remains challenging. $(2,3)$

Alternative to sternal resections, extensive curettage and PMMA have been used, even though it is less invasive procedure with low infection rates. It has a local recurrence rate of $25 \% \cdot(2,3)$ 
Over the past decade, the benefit of sternal or large chest wall resections were usually counterbalanced by high postoperative morbidity and mortality rates.

Mansour et al reported 7\% overall mortality with $24 \%$ rate of pneumonia and overall length of the stay of $18 \pm 6$ days after chest wall resection and reconstruction with the mesh.(4)

Indeed, lack of postoperative chest wall rigidity could lead on to paradoxical chest motion with acute respiratory failure, difficulty in weaning the patient from the ventilator and high risk of pneumonia. The rigidity of the chest wall cavity must be restored to diminish the severity of the complications.

Types of oncologic Sternectomies - University of Texas, MD Anderson Cancer Centre

- Type I - Partial Sternectomy.

- Type IIA - Subtotal Sternectomy sparing manubrium.

- Type IIB - Subtotal Sternectomy sparing Xiphisternum.

- Type IIC - Vertical Hemisternectomy.

- Type III - Total Sternectomy.

Chest wall reconstruction can be either a Primary Closure, Autogenous replacements, Synthetic replacements. Various methods of sternal reconstruction include use of steel bars and Marlex mesh; Marlex mesh with or without Methyl methacrylate; the use of acrylic resins and Gore-Tex soft tissue patch. When primary closure had not been possible, various myocutaneous and pedicled omental flaps have been used to close the defect. $(5,6,7)$

The ideal procedure requires only the minimum quantity of synthetic material and also avoids interfering with functions. The ideal prosthesis to replace the sternum should be rigid to protect the heart, malleable to accommodate the breathing and inert to allow the growth of fibrous tissue and decrease the likelihood of infections. ${ }^{(8)}$

Another innovative technique for sternal reconstruction is the allograft transplantation after special conditioning and tailoring. Allograft acts as a scaffold for the cell and new bone formation allowing excellent host incorporation.(9)

Reinforcement with rigid prosthesis such as methyl methacrylate or metallic plates are required to avoid anterior flail chest and protect mediastinal organs.(10)

Because of the absence of any complications in the intraoperative, postoperative and during the entire duration of the follow-up, the operative procedure we performed is a viable alternative method of reconstruction to others.

\section{CONCLUSION}

Combining an appropriate soft tissue reconstruction with reconstruction of the underlying sternectomy, skeletal defects allows even total sternectomies to be performed with acceptably low morbidity. The need of the patient is to be assessed on an individual basis and a collaborative effort on behalf of the ablative and reconstructive surgeons is imperative to provide the optimal management for these patients. The reported long-term local control of giant cell tumour of bone after surgical resection ranges from $73 \%$ to $100 \%$.(11) Contoured stainless steel plating with locking screws and a sandwich of prolene mesh with stainless steel wires and methyl methacrylate provide a good cosmetic and a functional result and a short hospital stay.

\section{REFERENCES}

1. Athanassiadi K, Kalavrouziotis G, Rondogianni D, et al. Primary chest wall tumours: early and long-term results of surgical treatment. Eur J Cardiothorac Surg 2001;19(5):589-93.

2. Unni KK: Giant cell tumour. In: Dahlin's bone tumours. General aspects and data on 11,087 cases. Unni KK (ed) Philadelphia, Lippincott-Raven 1996;20(10):263-83.

3. Gitelis S, McDonald DJ. Common benign bone tumours and usual treatment. In: surgery for bone and soft-tissue tumours. Simon MA, Springfield D (eds). Philadelphia, lippincott raven, 1998;181-205.

4. Mansour KA, Thourani VH, Losken A, et al. Chest wall resection and reconstruction: a 25-year experience. Ann Thorac Surg 2002;73(6):1720-5.

5. Pairolero PC. Chest wall tumours. In: Shields TW, LoCicero J, Ponn RB, editors. General thoracic surgery. Philadelphia: Lippincott Williams \& Wilkins 1999; $5^{\text {th }}$ ed:589-98.

6. Halm HF, Hoffmann C, Winkelmann W. The use of a gore-tex soft-tissue patch to repair large full-thickness defects after subtotal sternectomy a report of three cases. J Bone Joint Surg Am 2001;83-A(3):420-3.

7. Shimizu J, Nakamura Y, Tsuchida K, et al. Complete sternectomy for metastatic carcinoma with reconstruction using a latissimus dorsi musculocutaneous flap. Eur J Cardiothorac Surg 1995;9(6):342-4.

8. Gonfiotti A, Santini PF, Campanacci D, et al. Malignant primary chest-wall tumours: techniques of reconstruction and survival. Eur J Cardiothorac Surg 2010;38(1):39-45.

9. Dell'Amore A, Cassanelli N, Dolci G, et al. An alternative technique for anterior chest wall reconstruction: the sternal allograft transplantation. Interact Cardio Vasc Thorac Surg 2012;15(6):944-7.

10. Chapelier AR, Missana MC, Couturaud B, et al. Sternal resection and reconstruction for primary malignant tumours. Ann Thorac Surg 2004;77(3):1001-6.

11. Mendenhall W, Zlotecki R, Scarborough M, et al. Giant cell tumour of bone. Am J Clin Oncol 2006;29(1):96-9. 